\title{
Research on Information Construction Problems of Teaching Management in Higher Vocational College
}

\author{
Ying-Han LIU $1, a$ \\ ${ }^{1}$ Chongqing College of Electronic Engineering, China 400331 \\ aliuyinghan_lynn@163.com
}

Keywords: Higher Vocational College, teaching management, information

\begin{abstract}
With the development of science and technology and the continuous progress of society, people's life and work styles are moving towards the direction of modernization. The modernization level of carrying out work in Higher Vocational College is also constantly upgrading. Information construction of teaching management as an important content of school's modernization has already been a trend. However, how to do well in information construction of teaching management in Higher Vocational College has become a problem lying ahead that needs to be solved urgently. Based on this situation, the author puts forward some own ideas, hoping to provide some valuable references to related staff.

Carrying out a good teaching management work is significant for improving the quality of school personnel training. Strengthening information construction of teaching management could effectively promote the level of teaching management and improve work quality. But information construction of teaching management can not do without the support of capital, personnel, technology, management mechanism etc. [1] Thus it can be seen that we still have a long way to go on the road of information construction of teaching management. This study takes the important significance of information construction of teaching management in Higher Vocational College as the starting point and elaborates on the effective ways of realizing information construction of teaching management.
\end{abstract}

\section{Significance of Information Construction of Teaching Management in Higher Vocational College}

To be specific, the significance of information construction of teaching management in Higher Vocational College is mainly reflected in the following aspects: Firstly, the reform process of teaching management has been accelerated. Higher Vocational College should change ideas on teaching management, combine the practical facts of students and innovate the ways of reform. On the basis of applying computer technology, the characteristics of teaching management can be embodied, especially the humanized and scientific management mode. Secondly, standardize the process of teaching management and a standardized teaching management is proved to be an important method to ensure the quality of teaching. Therefore improving the information system of teaching management can bring every link of teaching management into standardization. [2]Finally, adopt scientific management mode. Many Higher Vocational Colleges have always followed the previous management mode in the process of carrying out teaching management work. However with the rapid development of education, traditional working mode can not meet the practical needs of today's society any more and an adoption of modern management mode is imperative.

\section{Effective Ways of Information Construction of Teaching Management in Higher Vocational College.}

\section{Making a Scientific Plan for Construction Process}

In order to organically integrate teaching management information construction into the whole process of school's information construction, school resources need to be highly shared. [3] Adopt a 
scientific plan for carrying out construction in batches according to the actual situation at school. No matter it is software platform or hardware facility, the construction should be carried out step by step. Speed up the process of teaching management reform while updating software and hardware facilities. In the process of system design and procurement, not only practicality should be paid attention to, but also the comprehensive trend of education reform and development should even be better combined. Higher Vocational College should organize teaching management professionals and computer network experts to deeply demonstrate the design scheme of the system and functional structure. In the process of system development, installation and debugging, teaching management business has to be understood. And computer technology professionals' participant in the entire process could ensure the normal running of the system.

\section{Actively Exploring New Management Ideas}

Constructing informational teaching management mode is not simply about introducing computer software, but requires cooperation between teachers and students in the whole school. Every teacher and student should be fully aware of the importance of teaching management information. Especially teaching administrators should keep up with the times and improve computer operation skills to reach the goal of being proficiency in computer management system. [4]At the same time, they could help teachers and students solve the problems they encounter while using computers. In this way, working efficiency is improved, timeliness and accuracy of information is ensured. The goal of promoting the process of information construction of teaching management is achieved smoothly. In addition, schools should also actively improve the related facilities, upgrade and renew the management platform timely, so that work efficiency can be improved.

\section{Reasonably Allocating Teaching Administrators}

It can be said that the process of information construction is a process of continuous innovation which places greater demands on teaching administrators. Under the new situation, teaching administrators should face challenges with a positive attitude; enrich teaching management concepts and experience constantly; take a correct attitude towards work; learn advanced education management methods and improve professional skills. However, the promotion of every teaching administrator's comprehensive quality requires long-time accumulation and internalization. To ensure the stability of teaching management staff in the early stage of information construction, Higher Vocational Colleges should allocate teaching administrators reasonably according to the condition of the post so that continuous power can be provided for information construction of teaching management in Higher Vocational College.

\section{Perfecting Examination and Evaluation Mechanism}

As has been said above, information construction of teaching management can not be completed at one stroke. That is to say, there is a long way to go. As the cornerstone of realizing information construction of teaching management, administrators could help school save a lot of maintenance costs with their occasional creative ideas. Meanwhile, a fault of administrators could cause mess to the system and then affect the overall working efficiency. As regard to such situation, Higher Vocational Colleges should actively perfect the assessment mechanism to assess and evaluate teaching administrators according to certain incentive mechanism and assessment method. If individual staff does not operate according to specific procedures, irresponsibly, to the extent that serious faults occur, this should be dealt with as teaching accident. [5]While for those administrators who are creative and make outstanding contributions should be given material rewards.

\section{Conclusion}

To summarize, exploring information construction of teaching management in Higher Vocational College to accelerate the construction speed is of certain realistic significance. Although some problems still exist in the process of carrying out related work at the present stage, teaching 
management quality can be improved and long and stable development of Higher Vocational College can be realized only if Higher Vocational Colleges actively explore new working modes, change working ideas, innovate working methods and perfect examination and evaluation mechanism.

\section{References}

[1] Yang Yu, Shi Daomin. Reflection and exploration on information platform construction of teaching management in Higher Vocational College [J]. Economic market of science and technology, 2014, (05): 58-59.

[2] Li Fuliang. Reflection and exploration on information integrated teaching management in Higher Vocational College [J].Vocational and teaching communication, 2014, (32): 63.

[3] Lou Guiling. Reflection and exploration on information construction of teaching management [J]. Journal of Zhong De vocational and technical college in Tian Jin, 2015, (06): 102-103.

[4] Li Jianying. Research on reform of information teaching mode in Higher Vocational College [J]. Data of culture and education, 2015(18):151-152

[5] Zhang Ying. Exploration of information instructional design and multimedia technology application in Higher Vocational College. Consumer electronics, 2013 (18): 229-229 